EPiC Series in Engineering
Volume 3, 2018, Pages 1406-1414
HIC 2018. 13th International
Conference on Hydroinformatics

\title{
Influence of Rainfall Data with Different Spatial Resolutions on Flood Forecasting Reliability
}

\author{
Mamoru Miyamoto $^{1 *}$ and Kazuhiro Matsumoto ${ }^{2}$ \\ ${ }^{1}$ International Centre for Water Hazard and Risk Management (ICHARM), Tsukuba, Japan \\ ${ }^{2}$ Fujitsu Laboratories LTD., Kawasaki, Japan \\ mmiyamoto@pwri.go.jp, matsumoto.ka-12@jp.fujitsu.com
}

\begin{abstract}
Recent advancements in precipitation observation technology make it possible to precisely describe the intensity and temporal-spatial distribution of heavy rainfall, which can cause severe floods and inundations. Such technologies have also increased the accuracy of flood forecasting. However, error factors in flood forecasting remain to be solved, originating in not only input data but also model structure and calibration. Thus, this study focused on convergence results of errors in parameter optimization of the PWRI Distributed Hydrological Model and the reproducibility of river discharge. The reliability of ground-gauge and C-band-radar rainfall is compared in terms of flood forecasting under the condition of the minimum error due to calibration. Although the convergence results showed that $\mathrm{C}$-band radar rainfall was superior to ground gauge rainfall, both were equally effective in reproducing river discharge with a high NSE of 0.9 at a station with error assessment. On the other hand, the reproducibility of river discharge with C-band radar data was highly superior to that with ground gauge data at a station without error assessment. This indicates that grid-based high resolution rainfall data is necessary for basin-wide flood forecasting.
\end{abstract}

\section{Introduction}

Timely and reliable flood forecasting is necessary for expeditious flood prevention and evacuation efforts. Reliable flood forecasting requires high-resolution, accurate rainfall as input data. Recent advancement in rainfall observation technology makes it possible to precisely describe the intensity and temporal-spatial distribution of heavy rainfall, which can cause severe floods and inundations. Studies have been conducted to clarify how the spatial resolution of rainfall data influences flood simulation.

\footnotetext{
${ }^{*}$ Corresponding author, Tel.: +81-29-879-6779; Fax: +81-29-879-6709
} 
Sangati et al. [1] investigated the sensitivity of flash flood simulation to the spatial resolution of rainfall at catchment scales ranging from $10.5 \mathrm{~km} 2$ to $623 \mathrm{~km} 2$. The effect of spatial rainfall aggregation was quantified using a dimensionless parameter represented by the ratio of the rainfall resolution to the characteristic basin length. Zoccatelli et al. [2] showed that neglecting spatial rainfall variability results in a considerable loss of the simulation Nash-Sutcliffe Efficiency (NSE) in almost 30\% of the cases studied in their research (NS: less than 0.8); one of the cases showed an even smaller NS, less than 0.6. Thus, subsequent studies assessed the influence of the spatial resolution of rainfall input on hydrological models. However, error factors of flood forecasting include model structure and calibration, but not input data. In this context, this study focused on convergence results of errors in parameter optimization of the PWRI Distributed Hydrological Model and the reproducibility of river discharge. Ground gauge rainfall and C-band radar rainfall were compared in reliability as input data for flood forecasting under the condition of the minimum error due to calibration.

\section{Methodology}

\subsection{Target River Basin}

The Abe River basin is located in Shizuoka Prefecture in Japan. There are 13 rainfall gauges and three water-level gauges in the Abe River basin with a catchment area of $567 \mathrm{~km} 2$. Figure 1 shows the locations of hydrological gauges in the river basin. Eight floods which recorded a river discharge of more than $1000 \mathrm{~m} 3 / \mathrm{s}$ at the Tegoshi station after 2007 were selected as target floods in this study. Table 1 shows the details of the target flood events.

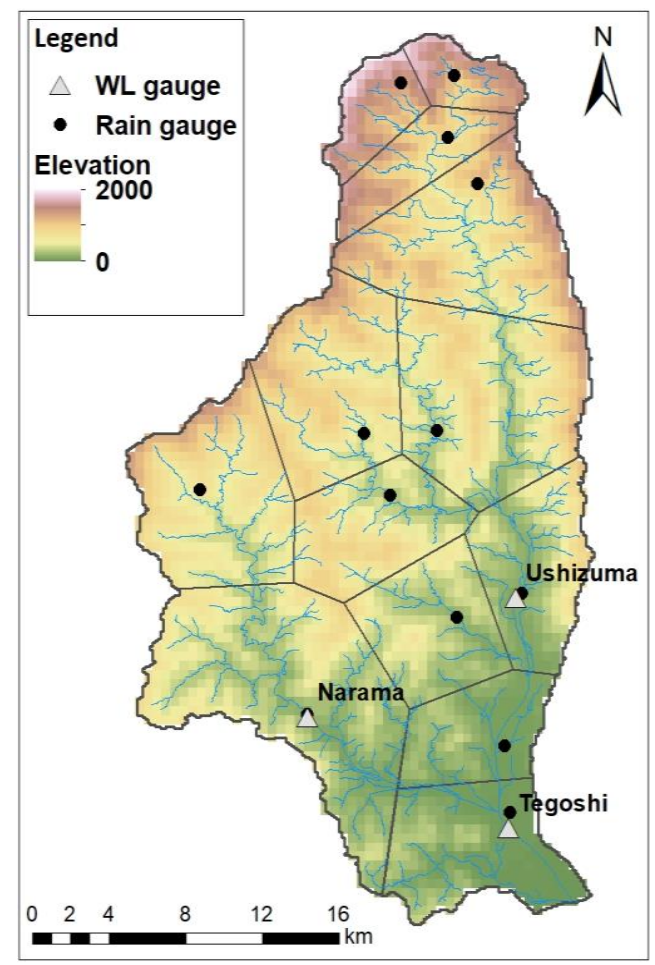

Figure 1: Hydrological stations in the Abe River basin 


\begin{tabular}{llccc}
\hline \multicolumn{1}{c}{ Date } & $\begin{array}{c}\text { Duration } \\
(\text { days })\end{array}$ & $\begin{array}{c}\text { Total Rainfall } \\
(\mathrm{mm})\end{array}$ & $\begin{array}{c}\text { Maximum Discharge } \\
\left(\mathrm{m}^{3} / \mathrm{s}\right)\end{array}$ \\
\hline Flood-1 & $2007 / 7 / 13-18$ & 6 & 365.7 & 2351 \\
Flood-2 & $2011 / 7 / 18-23$ & 6 & 406.1 & 1467 \\
Flood-3 & $2011 / 8 / 31-9 / 7$ & 8 & 478.9 & 1313 \\
Flood-4 & $2011 / 9 / 16-23$ & 8 & 508.1 & 3501 \\
Flood-5 & $2011 / 11 / 19-21$ & 3 & 190.0 & 1168 \\
Flood-6 & $2012 / 6 / 19-21$ & 3 & 248.3 & 2474 \\
Flood-7 & $2012 / 7 / 11-16$ & 6 & 284.1 & 1301 \\
Flood-8 & $2014 / 10 / 5-7$ & 3 & 379.8 & 3860 \\
\hline
\end{tabular}

Table 1: List of the target flood events

\subsection{Rainfall Data}

Error in the calculation of basin-wide average rainfall due to the number of gauges was assessed in order to clarify the uncertainty in terms of spatial distribution of ground gauges. Figure 2 shows the relationship between representative area per gauge and error in basin-wide average rainfall regarding the eight target floods. Basin-wide average rainfall in each representative area was calculated with the Monte Carlo method by assuming the number of rainfall gauges $n(n=1,2, \ldots, 13)$ in the basin. According to the average line in Figure 2, the error is below 0.2 with less than $400 \mathrm{~km} 2$ of representative area; below 0.1 with less than $150 \mathrm{~km} 2$. This result based on hourly rainfall corresponds to the finding in past research by the U. S. Weather Bureau [3] using daily rainfall.

Figure 3 compares the spatial distributions of Flood-4 rainfall data from ground gauges and C-band radar. The accumulated basin-mean of the gauged rainfall was $508.1 \mathrm{~mm}$, while that of the radar-based rainfall was $608.7 \mathrm{~mm}$. The gauged observation cannot describe a detailed spatial distribution; on the other hand, the radar-based observation can show a more elaborate spatial distribution, including intense rain areas, based on a $1 \mathrm{~km}$ grid. However, belt-like abnormal areas estimated due to ground clutter appear in the south-western part of the basin. Hence, the comparison found that both ground gauge rainfall and C-band radar rainfall include error. 
Influence of Rainfall Data with Different Spatial Resolutions on ... M. Miyamoto and K. Matsumoto

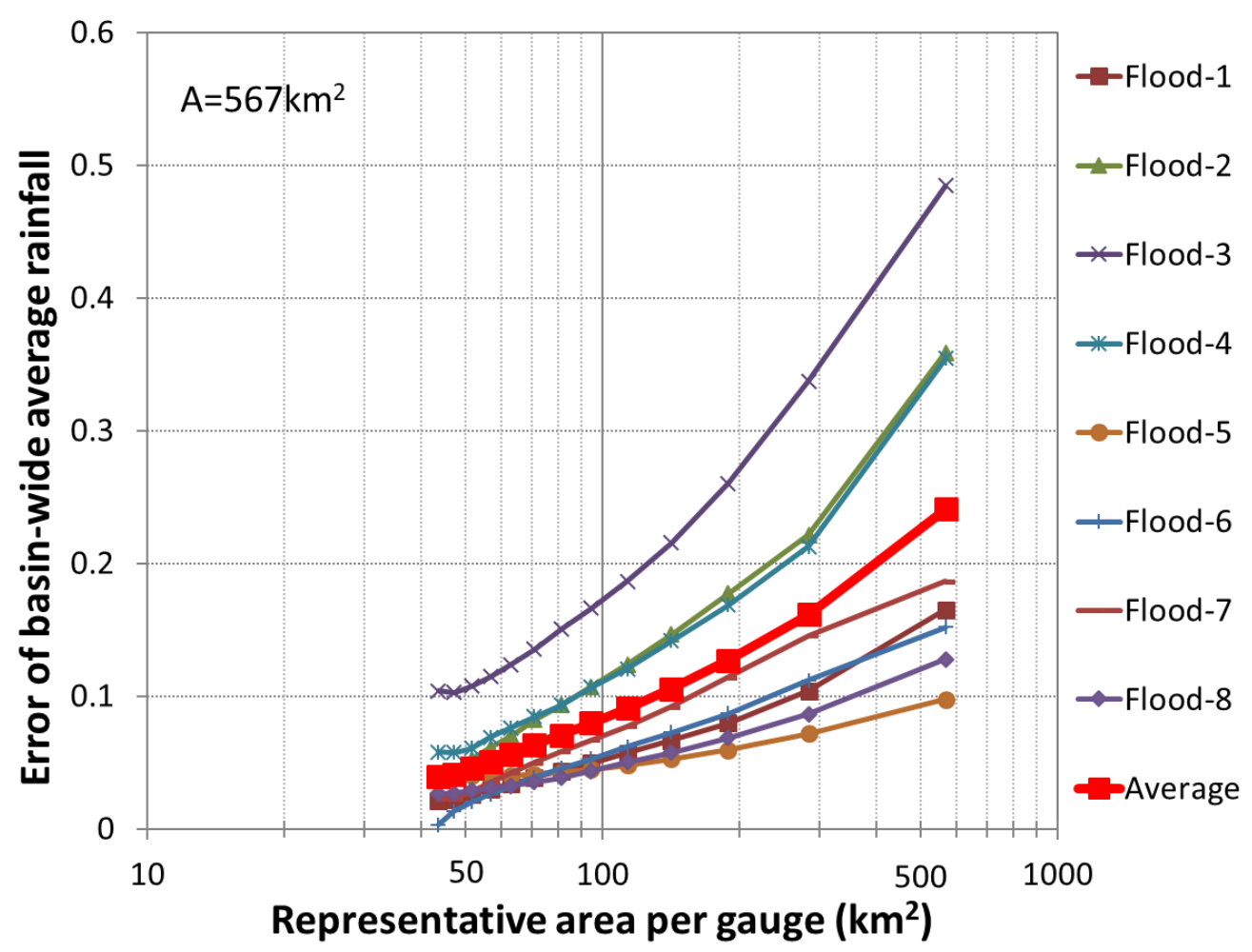

Figure 2: Relationship between representative area per gauge and error in basin-wide average rainfall
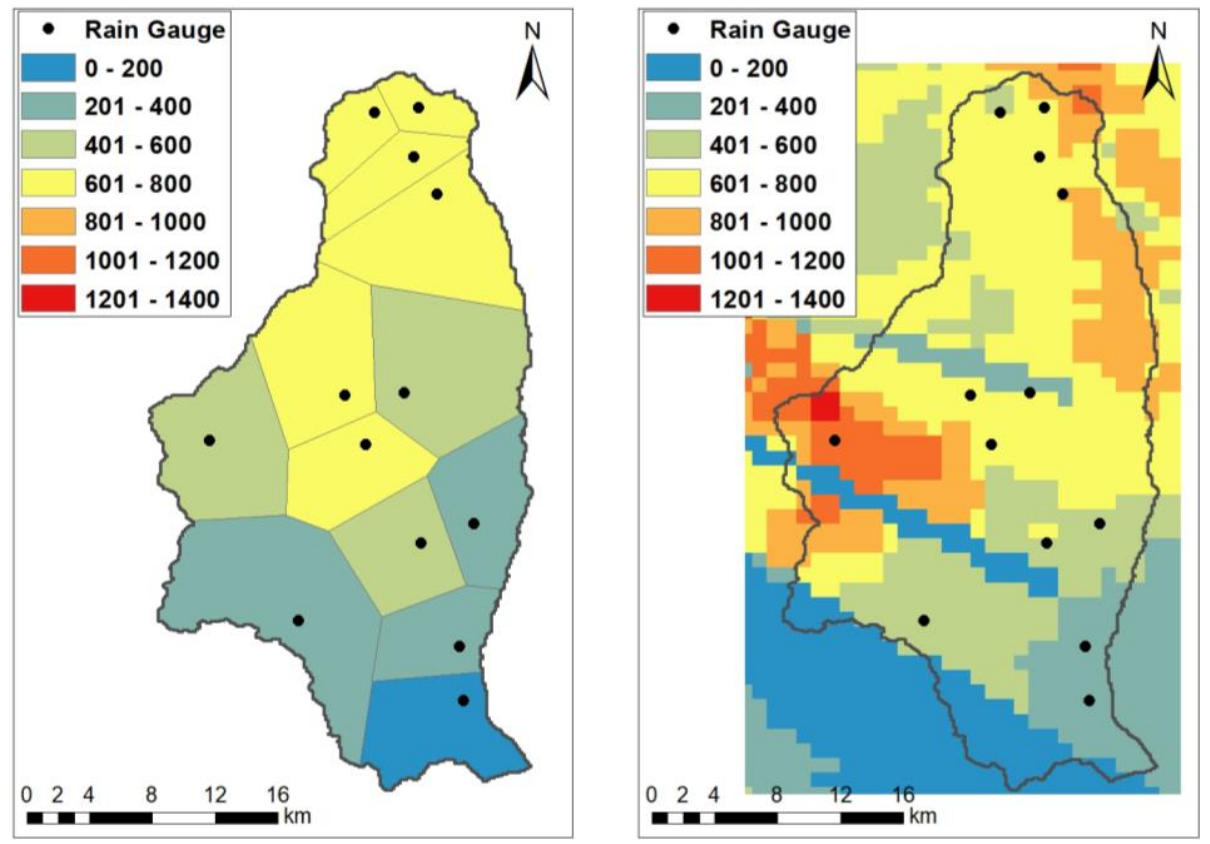

Figure 3: Spatial distributions of rainfall from ground gauges and C-band radar 


\subsection{Flood Forecasting Model}

\subsubsection{IFAS}

The Integrated Flood Analysis System (IFAS) was developed and has been improved by ICHARM to conduct effective flood forecasting particularly in insufficiently-gauged river basins. IFAS employs the Public Works Research Institute Distributed Hydrological Model (PDHM) as its runoff simulation model. Figure 4 illustrates the conceptual structure of PDHM. The model calculates surface flow, rapid subsurface flow, infiltration, slow subsurface flow and base flow in terms of the equations (1) - (5).

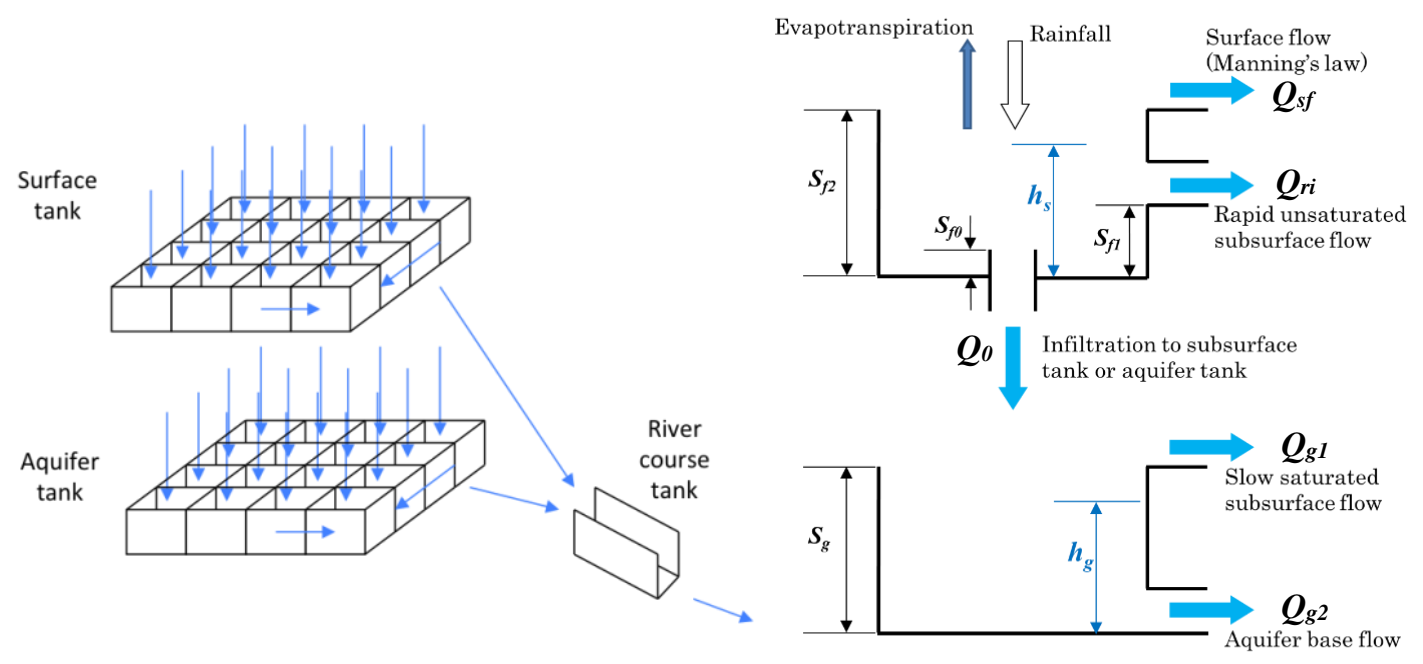

Figure 4: Conceptual structure of PDHM

$Q_{s f}=L \frac{1}{N}\left(h-S_{f 2}\right)^{\frac{5}{3}} \sqrt{i}$

$Q_{r i}=\alpha_{n} \cdot A \cdot f_{0} \frac{\left(h-S_{f 1}\right)}{\left(S_{f 2}-S_{f 1}\right)}$

$Q_{0}=A \cdot f_{0} \frac{\left(h-S_{f 0}\right)}{\left(S_{f 2}-S_{f 0}\right)}$

$Q_{g 1}=A_{u}^{2} \cdot\left(h-S_{g}\right)^{2} \cdot A$

$Q_{g 2}=A_{g} \cdot h \cdot A$

where $Q_{s f}$ : surface flow $\left(\mathrm{m}^{3} / \mathrm{s}\right), L$ : mesh length $(\mathrm{m}), N$ : surface roughness coefficient $\left(\mathrm{m}^{-1 / 3} \mathrm{~s}\right), h$ : water height for the tank $(\mathrm{m}), S_{f 2}$ : height from which surface flow occurs $(\mathrm{m}), i$ : slope with the adjacent cell, $Q_{r i}$ : rapid unsaturated subsurface flow $\left(\mathrm{m}^{3} / \mathrm{s}\right), \alpha_{n}$ : runoff coefficient of rapid intermediate flow (-), $A$ : mesh area $\left(\mathrm{m}^{2}\right), f_{0}$ : final infiltration capacity $(\mathrm{cm} / \mathrm{s}), S_{f l}$ : height from which rapid unsaturated subsurface 
flow occurs (m) $Q_{0}$ : infiltration to aquifer tank ( $\left.\mathrm{m}^{3} / \mathrm{s}\right), S_{f 0}$ : height where ground infiltration occurs $(\mathrm{m})$, $Q_{g l}$ : slow saturated subsurface flow $\left(\mathrm{m}^{3} / \mathrm{s}\right), A_{u}$ : runoff coefficient of slow intermediate flow $\left((1 / \mathrm{mm} / \text { day })^{1 / 2}\right), S_{g}$ : height from which slow saturated subsurface flow occurs $(\mathrm{m}), Q_{g 2}$ : base flow $\left(\mathrm{m}^{3} / \mathrm{s}\right)$, $A_{g}$ : base flow coefficient (1/day). River tank gathers each component of flows from both tanks calculated by equations (1) - (5) for river discharge calculation. In the process of river routing, the Kinematic Wave method is employed as the river course tank model for simulating river discharge.

\subsubsection{Parameter Optimization}

Parameter optimization was performed on six hydrological parameters of the model; final infiltration capacity f0, height from which surface flow occurs Sf2, surface roughness coefficient $\mathrm{N}$, runoff coefficient of rapid intermediate flow an, runoff coefficient of slow intermediate flow $\mathrm{Au}$, and base flow coefficient Ag. The search range of each parameter was limited to a physically appropriate value as shown in Table 2 . Even though the different values of final infiltration capacity and surface roughness were applied according to land-use type, only the value of forest type was included in the optimization because the forest was a dominant type in the basin. ALPSO and SDPEN, the solvers of pyOpt [4], were applied in the optimization based on the results from previous research of the authors [5]. Error assessment was conducted with a mean square error shown as the following equation (6) by comparing observed and simulated discharges at the Tegoshi station.

\begin{tabular}{lccc}
\hline Parameter & Unit & $\begin{array}{c}\text { Maximum } \\
\text { limit }\end{array}$ & $\begin{array}{c}\text { Minimum } \\
\text { limit }\end{array}$ \\
\hline Final infiltration capacity $f_{0}$ & & $1.0^{*} 10^{-2}$ & $1.0^{*} 10^{-5}$ \\
Height from which surface flow occurs $S_{f 2}$ & $\mathrm{~cm} / \mathrm{s}$ & 1.0 & 0.01 \\
Ground surface roughness $N$ & $\mathrm{~m}$ & 2.0 & 0.1 \\
Runoff coefficient of rapid intermediate flow $\alpha_{n}$ & - & 1.0 & 0 \\
Runoff coefficient of slow intermediate flow $A_{u}$ & $(1 / \mathrm{mm} / \mathrm{day})^{1 / 2}$ & 0.6 & 0.01 \\
Base flow coefficient $A_{g}$ & $1 /$ day & 0.1 & 0.0001 \\
\hline
\end{tabular}

Table 2: Search range of parameter optimization

$E_{M}=\frac{1}{n} \sum_{i=1}^{n}\left(Q_{o i}-Q_{c i}\right)^{2}$

\section{Results and Discussion}

Analysis found a significant result on Flood-4 regarding error convergence in hydrological parameter optimization of PDHM with ground gauges and C-band radar. Figure 5 shows the convergence results of errors in parameter optimization in Flood- 4 according to types of rainfall data and optimization algorithms. The convergent errors of optimization with C-band radar data are fewer than those with ground gauge data regardless of the types of optimization algorithms. More specifically, the radar-based optimization can reduce errors down to as few as 5000 by parameter tuning, while the gauge-based optimization can reduce errors only down to 10000. Consequently, C-band radar can lead to more accurate simulation for flood discharge reproduction. However, according to Figure 6, which shows the highest reproducible results of river discharge at the Tegoshi station, the difference between the gauge-based discharge and the radar-based discharge is not critical in terms of flood hydrograph 
because both simulated river discharges show a good agreement with the observed discharge. The calculated NSE was quite high in both simulations; 0.988 for C-band radar and 0.967 for ground gauges.

Although the results of ground gauges and C-band radar show high performance in flood discharge reproduction at the Tegoshi station, a different result is found in respect of basin-wide flood forecasting. Figure 7 shows the reproducible results of river discharge at the Narama station, where no error assessment was performed. The simulated discharge at the Narama station with C-band radar data shows a good agreement with the observed discharge, while the simulation with ground gauge data underestimates the discharge, i.e., lower than half the observed discharge. The NSE of the radar-based simulation was 0.918 and that of the gauge-based simulation was 0.751 . This result indicates that $\mathrm{C}$ band radar data produces better results for basin-wide forecasting.

Table 3 shows the NSEs of the reproduced river discharges for all target flood events at the three stations. The table indicates the greater values found from comparison between ground gauge-based and C-band radar-based NSE in boldface when they are more than 0.7. Although the better rainfall input in respect of reproducibility at the Tegoshi station alternates at a very high NSE level between ground gauges and C-band radar, depending on the flood events, radar-based simulation shows better reproducibility than ground gauge-based simulation for almost all events at the Narama station where the distribution of ground gauges is relatively sparse. At the Ushizuma station, since both simulations show low reproducibility overall, the reliability for the observed discharge is questionable probably due to the rating curve. Thus, both simulations with ground gauge and $\mathrm{C}$-band radar rainfall can accurately reproduce the river discharge at an error-assessment point by parameter tuning, while $\mathrm{C}$-band radar rainfall also produces accurate results at a no error-assessment point.

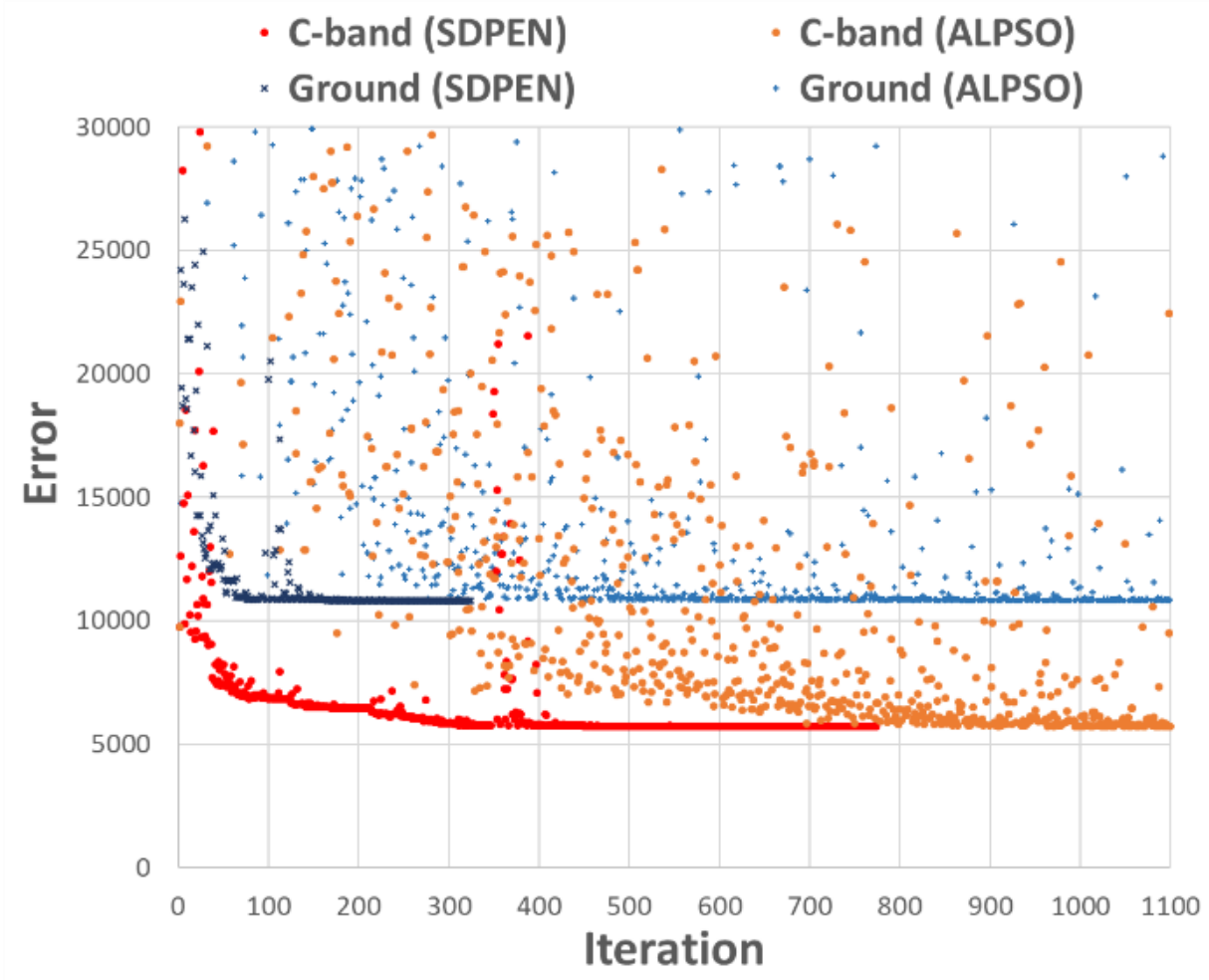

Figure 5: Convergence result of errors in parameter optimization 
Influence of Rainfall Data with Different Spatial Resolutions on ... M. Miyamoto and K. Matsumoto

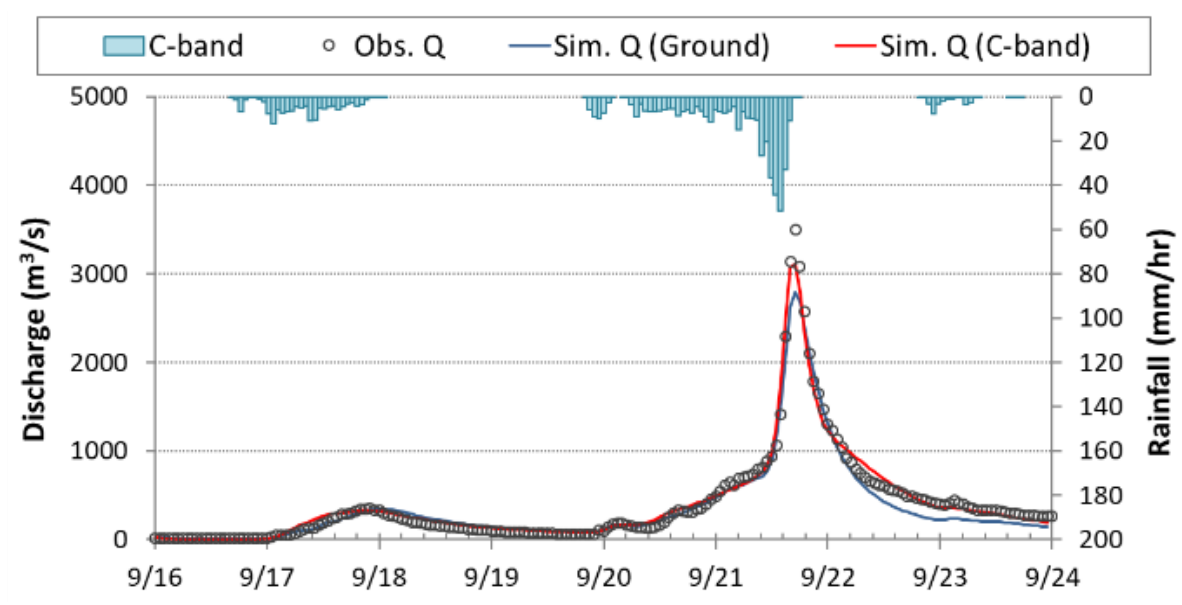

Figure 6: Reproducible results of river discharge at Tegoshi station

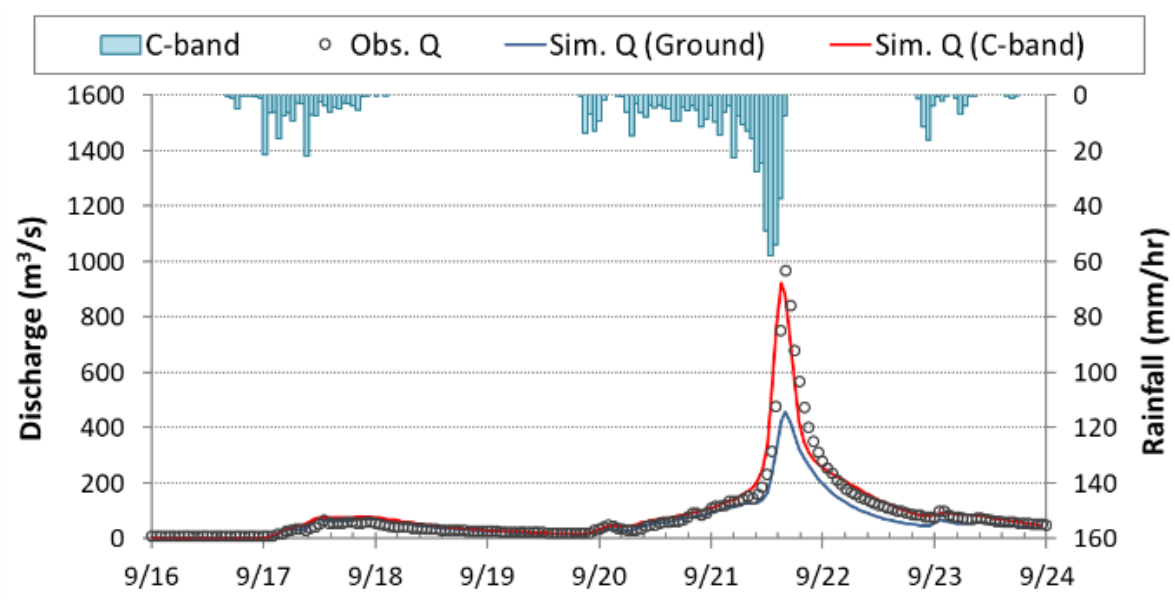

Figure 7: Reproducible results of river discharge at Narama station

\begin{tabular}{lcccccc}
\hline & \multicolumn{2}{c}{ Tegoshi station } & \multicolumn{2}{c}{ Narama station } & \multicolumn{2}{c}{ Ushizuma station } \\
\cline { 2 - 7 } & Ground & C-band & Ground & C-band & Ground & C-band \\
\hline Flood-1 & $\mathbf{0 . 9 7 7}$ & 0.963 & 0.847 & $\mathbf{0 . 8 9 3}$ & $\mathbf{0 . 8 5 8}$ & 0.842 \\
Flood-2 & $\mathbf{0 . 9 6 9}$ & 0.948 & 0.606 & $\mathbf{0 . 7 5 1}$ & 0.571 & 0.518 \\
Flood-3 & 0.916 & $\mathbf{0 . 9 8 5}$ & 0.781 & $\mathbf{0 . 9 7 2}$ & 0.159 & 0.495 \\
Flood-4 & 0.967 & $\mathbf{0 . 9 8 8}$ & 0.751 & $\mathbf{0 . 9 1 8}$ & -4.953 & -3.979 \\
Flood-5 & $\mathbf{0 . 9 8 5}$ & 0.983 & 0.863 & $\mathbf{0 . 9 3 8}$ & -0.073 & -0.568 \\
Flood-6 & $\mathbf{0 . 9 6 9}$ & 0.953 & 0.692 & $\mathbf{0 . 8 2 3}$ & $\mathbf{0 . 7 9 4}$ & 0.730 \\
Flood-7 & $\mathbf{0 . 8 1 7}$ & 0.790 & 0.672 & $\mathbf{0 . 7 5 5}$ & 0.556 & 0.606 \\
Flood-8 & $\mathbf{0 . 9 6 3}$ & 0.926 & 0.590 & 0.413 & 0.594 & 0.537 \\
\hline
\end{tabular}

Table 3: NSEs of river discharge for nast eight floods 


\section{Conclusion}

This study evaluated the performance of rainfall data with different spatial resolutions, i.e., data from ground gauges and C-band radar. The data underwent parameter optimization using a distributed hydrological runoff model. Although the convergence result of errors in parameter optimization showed only a slight advantage of data from C-band radar relative to those from ground gauges, the simulated discharge with C-band radar data showed a much better agreement with the observed discharge at the station where no error assessment was conducted than the simulated discharge with ground gauge data. In conclusion, both simulations with ground gauge rainfall and C-band radar can accurately reproduce the river discharge at an error-assessment point by well-conducted parameter tuning, while the simulation with C-band radar rainfall can produces accurate results at a no error assessment point. This indicates that grid-based high resolution rainfall data can contribute to more reliable basin-wide flood forecasting.

\section{References}

[1] Sangati, M. and Borga, M. (2009). Influence of rainfall spatial resolution on flash flood modeling. Nat. Hazards Earth Syst. Sci. 9, 575-584.

[2] Zoccatelli, D., Borga, M., Zanon, F., Antonescu, B., and Stancalie, G. (2010). Which rainfall spatial information for flash flood response modelling? A numerical investigation based on data from the Carpathian range, Romania, J. Hydrol., 394(1-2), 148-161.

[3] U. S. Weather Bureau (1974). The reliability of areal rainfall determination, Hydrometeorological Report, No. 5.

[4] pyOpt website, http://www.pyopt.org/reference/citing.html.

[5] Matsumoto, K., Miyamoto, M., Yamakage, Y., Tsuda, M., Yanami, H., Anai, H., and Iwami, Y. (2016). Parameter identification to estimate discharges of multiple water level stations using Colleo optimization software, Procedia Engineering, Vol. 154, 1283-1290. 